\title{
Importance of sample preheating in oxidation of $\mathrm{Ge}_{x} \mathrm{Si}_{1-x}$
}

W. S. Liu, E. W. Lee, a) and M-A. Nicolet

California Institute of Technology, Pasadena, California 91125

V. Arbet-Engels and K. L. Wang
University of California, Los Angeles, California 90024

(Received 9 September 1991; accepted for publication 27 December 1991)

Wet thermal oxidation at $1000^{\circ} \mathrm{C}$ of a 470 -nm-thick epitaxial $\mathrm{Ge}_{0.36} \mathrm{Si}_{0.64}$ layer on (100) $\mathrm{Si}$ produces oxides of different composition depending on the details of the oxidation procedure. When a cold sample is directly exposed to the hot steam, the surface layer of the oxide contains both $\mathrm{Ge}$ and $\mathrm{Si}$. Only $\mathrm{SiO}_{2}$ forms if a preheated sample is exposed to the hot steam. The effect is not present for dry oxidation and is attributed to the known enhancement of the wet oxidation rate by Ge, coupled with the transient warm up of a sample when it is immersed cold in hot steam.

Heterostructures of $\mathrm{Ge}-\mathrm{Si}$ are of interest because of their potentially useful optical and electronic properties. For the GeSi technology, the properties of the oxide formed by this material are critical. Several studies of the oxidation of $\mathrm{GeSi}$ have been published. ${ }^{1-8}$ Most authors ${ }^{1-6}$ observed the growth of a pure $\mathrm{SiO}_{2}$ layer with an enhanced oxidation rate in wet oxygen when compared to that of pure silicon, and a pileup of Ge below the oxide/ semiconductor interface. The alloys they used, however, were relatively light in Ge content and the oxidation temperatures were high. In the two most recent studies, $\mathrm{Ge}$ was found to be oxidized as well with GeSi alloys of high Ge content ${ }^{7}$ or at low temperature, ${ }^{8}$ due to the insufficient supply of $\mathrm{Si}$ at the interface with a much enhanced oxidation rate. In fact, $\mathrm{Ge}$ can also be oxidized on alloys of low Ge content if the temperature is low enough. ${ }^{8}$ Care must be exercised, however, when performing such oxidation experiments. The details of the procedure affects the results in ways that significantly modify their correct interpretation. The present work demonstrates the importance of the procedure in the oxidation of GeSi. Similar effects have previously been noticed in the oxidation of silicides. ${ }^{9}$

The samples used in this study were pieces of a 470-nm film of $\mathrm{Ge}_{0.36} \mathrm{Si}_{0.64}$ grown epitaxially on a (100)Si substrate by molecular beam epitaxy. The film is elastically relaxed as determined from $\mathrm{x}$-ray double-crystal diffractrometry. The samples were oxidized in a tube furnace at $1000{ }^{\circ} \mathrm{C}$ in dry oxygen or in wet oxygen obtained by bubbling nitrogen gas through $95^{\circ} \mathrm{C}$ water. Two oxidation procedures were used. In the first, the furnace was flushed with the oxidant, followed by introducing the cold sample into the hot furnace. In the second oxidation procedure (referred subsequently the method with preheating) the hot tube was flushed with nitrogen for approximately $1 \mathrm{~h}$. The sample was then introduced into the furnace. After about $10 \mathrm{~min}$, the furnace atmosphere was switched from nitrogen to the oxidizing ambient. The samples were analyzed after oxidation by backscattering spectrometry.

\footnotetext{
a) Permanent address: Department of Physics, Kyungpook National University, Taegu, Korea.
}

Figure 1 compares the backscattering spectra of two samples oxidized at $1000^{\circ} \mathrm{C}$ in wet oxygen with and without preheating. It is clear that with preheating only $\mathrm{SiO}_{2}$ is formed and that $\mathrm{Ge}$ piles up behind it. However, the oxide formed without preheating obviously includes Ge initially. To explain this difference we note that below $700^{\circ} \mathrm{C}$ in wet oxygen, $\mathrm{Ge}$ and $\mathrm{Si}$ are immobile compared to the oxidation

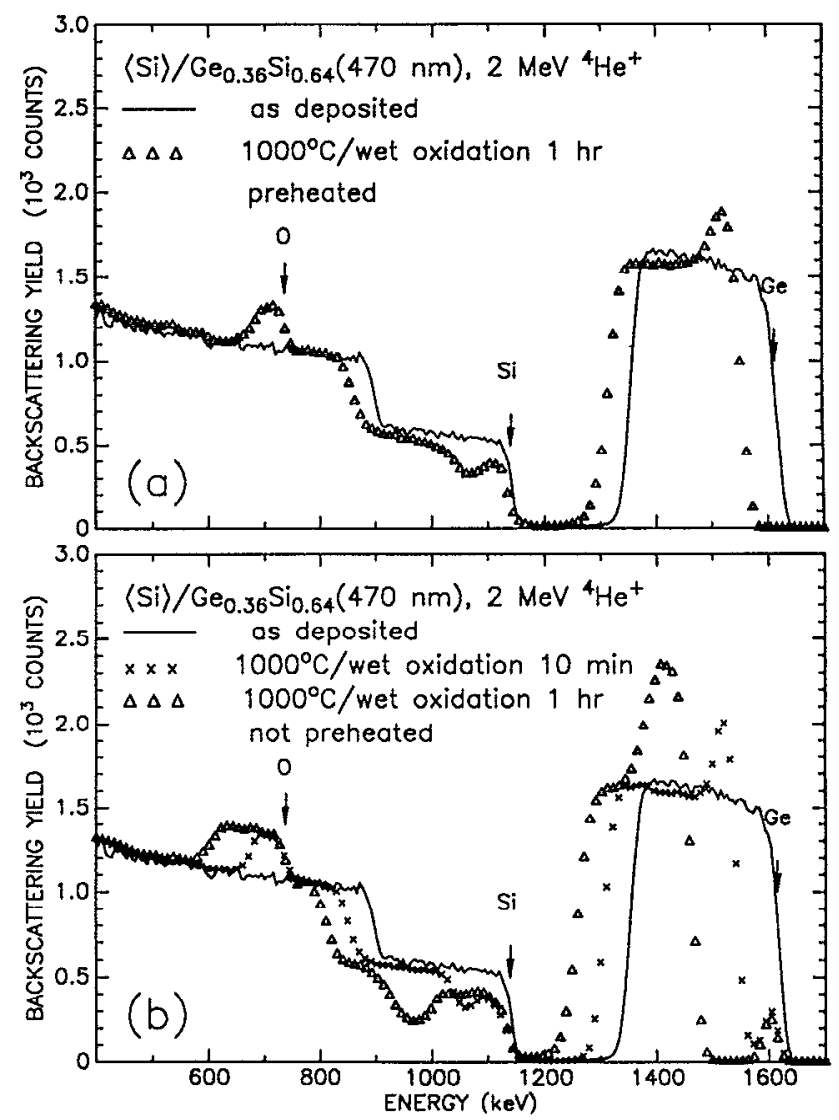

FIG. 1. 2-MeV ${ }^{4} \mathrm{He}^{+}$backscattering spectra of epitaxial $\mathrm{Ge}_{0.36} \mathrm{Si}_{0.64}$ films on (100)Si oxidized in steam at $1000^{\circ} \mathrm{C}$ : (a) after $1 \mathrm{~h}$ with preheating, (b) after $10 \mathrm{~min}$ and $1 \mathrm{~h}$ without preheating, showing no Ge oxidized after the first few minutes (when temperature reaches $1000^{\circ} \mathrm{C}$ ). 

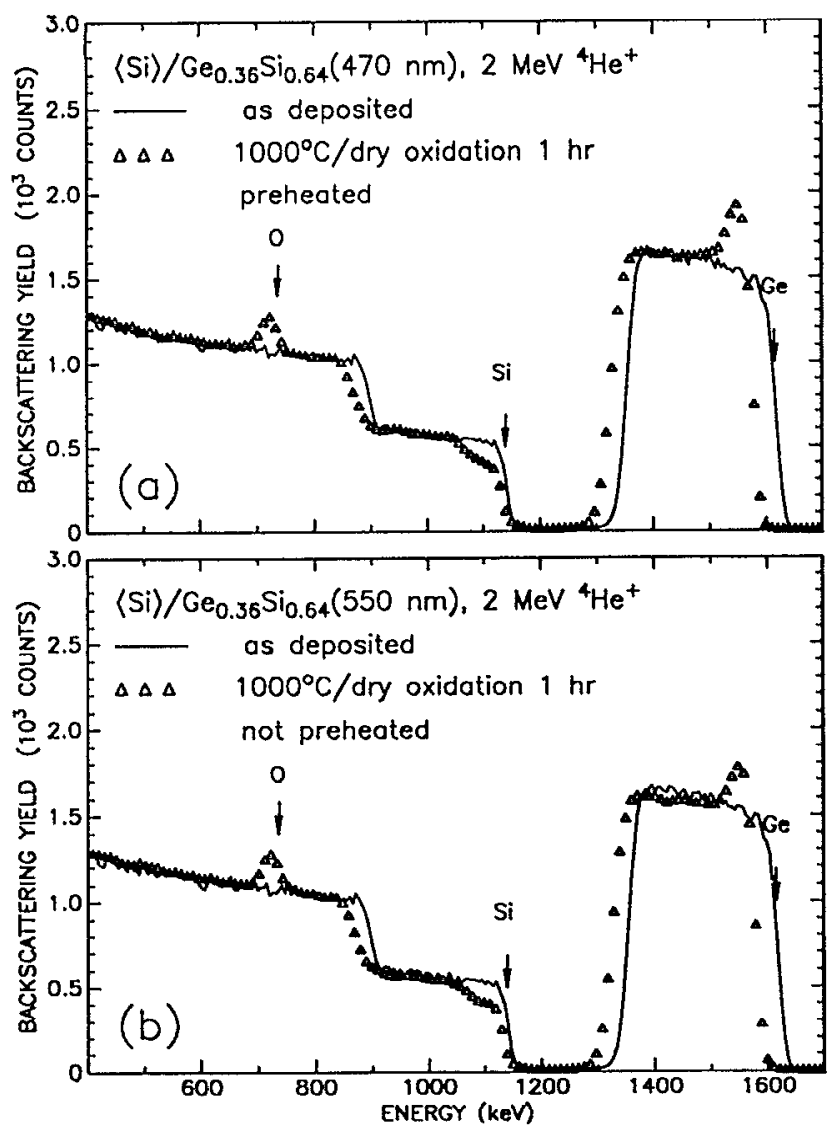

FIG. 2. 2-MeV ${ }^{4} \mathrm{He}^{+}$backscattering spectra of epitaxial $\mathrm{Ge}_{0.36} \mathrm{Si}_{0.64}$ films on (100) Si oxidized for $1 \mathrm{~h}$ in dry oxygen at $1000^{\circ} \mathrm{C}$ : (a) with preheating, (b) without preheating.

velocity. Ge as well as $\mathrm{Si}$ are oxidized in this temperature range and the reaction rate is quite large. ${ }^{8}$ The samples oxidized without preheating pass transiently through this temperature range as they warm up and incorporate $\mathrm{Ge}$ into the initially growing oxide. As the temperature rises further, the diffusivities of $\mathrm{Ge}$ and $\mathrm{Si}$ in $\mathrm{GeSi}$ increase so that $\mathrm{Ge}$ begins to be rejected and pure $\mathrm{SiO}_{2}$ is ultimately formed at $1000^{\circ} \mathrm{C}$. The Ge concentration profile in the oxide measured from the surface thus reaches a maximum and then decays. Although the heating rate of the samples is fast (on the order of $1000^{\circ} \mathrm{C} / \mathrm{min}$ ), the oxidation rate is large enough to incorporate significant amounts of $\mathrm{Ge}$ into the oxide in this first few minutes of the transient warm up. Figure 1(b) indeed shows that the Ge is incorporated into the oxide during the first few minutes; only $\mathrm{SiO}_{2}$ forms after this initial period when the temperature nears $1000{ }^{\circ} \mathrm{C}$.

In contrast to the wet oxidation behavior just discussed, Fig. 2 shows that in dry oxygen preheating is of no consequence. No $\mathrm{Ge}$ is contained in the oxide for either oxidation method. This outcome is explained by the fact that the oxidation rate in dry oxygen is much less than that in wet oxygen. The oxidation rate in dry oxygen is so small that an insignificant amount of $\mathrm{GeSi}$ is oxidized during the initial heating-up transient.

To place a cold sample in a hot oxidizing furnace clearly complicates the correct interpretation of the oxidation data in the case of GeSi. It is therefore prudent to preheat the samples before it is oxidized and adopt this as a standard one.

This work was supported by the Semiconductor Research Corporation under a coordinated research program at Caltech (91-SJ-100) and at UCLA (91-SJ-088). We thank R. Gorris for technical assistance.

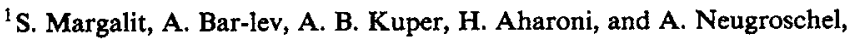
J. Cryst. Growth 17, 288 (1972).

${ }^{2}$ O. W. Holland, C. White, and D. Fathy, Appl. Phys. Lett. 51, 520 (1987).

${ }^{3}$ D. Fathy, O. W. Holland, and C. White, Appl. Phys. Lett. 51, 1337 (1987).

${ }^{4}$ O. W. Holland, C. W. White, and D. Fathy, Materials Research Society Symposium Proceedings (Materials Research Society, Pittsburgh, PA, 1988), Vol. 105, p. 271.

${ }^{5}$ F. K. LeGoues, R. Rosenberg, T. Nguyen, F. Himpsel, and B. S. Meyerson, J. Appl. Phys. 65, 1724 (1989).

${ }^{6}$ F. K. LeGoues, R. Rosenberg, and B. S. Meyerson, Appl. Phys. Lett. 54, 644 (1989).

${ }^{7}$ J. Eugene, F. K. LeGroues, V. P. Kesan, S. S. Iyer, and F. M. d'Heurle, Appl. Phys. Lett. 59, 78 (1991).

${ }^{8}$ W. S. Liu, G. Bai, M-A. Nicolet, C. H. Chern, V. Arbet, and K. L. Wang, in Proceedings of 1991 MRS Spring Meeting, edited by J. C. Bean, E. H. Parker, S. Iyer, Y. Shiraki, E. Kasper, and K. Wang (Materials Research Society, Pittsburgh, PA, 1991).

${ }^{9}$ W. J. Strydom and J. C. Lombaard, Thin Solid Films 131, 215 (1985). 